\title{
Two-stage exchange Arthroplasty for knee Periprosthetic joint infection exhibit high infection recurrence rate in patients with chronic viral hepatitis
}

Jui-ping Chen ${ }^{1,2}$, Chih-hsiang Chang ${ }^{1,2,3}$, Yu-chih Lin ${ }^{1,3}$, Sheng-hsun Lee ${ }^{1,2,3}$, Hsin-nung Shih ${ }^{1,3}$ and Yuhan Chang ${ }^{1,2,3,4^{*}}$

\begin{abstract}
Background: Currently, there is little evidence about the outcome of two-stage exchange arthroplasty for the treatment of knee periprosthetic joint infection (PJI) in patients with chronic viral hepatitis. To evaluate it, we set the primary outcome as infection recurrence, and the secondary outcome as the difference between patients diagnosed with hepatitis B virus or hepatitis C virus.

Patients and methods: Between June, 2010 and December, 2016, 172 patients with knee PJls were treated with two-stage exchange arthroplasty at our institute. Treatment success was defined using Delphi-based consensus. These patients were further divided into groups with or without chronic hepatitis. Variables were analyzed, including age, sex, comorbidities, microbiology, and operative methods. Minimum follow-up was 12 months (mean, 35 months; range, 12-85 months).

Results: Of the 172 knee PJ patients, 25 were identified with chronic hepatitis. The infection recurrence rate in the hepatitis group (28\%, 7 in 25) was significantly higher than that in the non-hepatitis group (9.5\%, 14 in 147), $p=$ 0.017. However, there was no significant difference in the infection recurrence rates between patients with HBV (24\%, 4 in 16) and HCV (33.3\%, 3 in 9). Regarding the outcomes of patients with infection recurrence, 4 of the nonhepatitis patients were treated with the debridement, antibiotic treatment, irrigation, and retention of prosthesis (DAIR) procedure, with a success rate of $75 \%$. The other 17 patients ( 7 with hepatitis and 10 without) were treated with repeated two-stage exchange arthroplasty with 100\% infection elimination rate until the final follow-up.
\end{abstract}

Conclusions: Knee PJI patients with chronic hepatitis have higher infection recurrence rate after two-stage exchange arthroplasty (28\%).

\footnotetext{
*Correspondence: yhchang@adm.cgmh.org.tw; yuhanchang2012@gmail.com

'Department of Orthopaedic Surgery, Chang Gung Memorial Hospital,

Linkou, Taiwan

${ }^{2}$ College of Medicine, Chang Gung University, Taoyuan, Taiwan

Full list of author information is available at the end of the article
}

C C The Author(s). 2021 Open Access This article is licensed under a Creative Commons Attribution 4.0 International License, which permits use, sharing, adaptation, distribution and reproduction in any medium or format, as long as you give appropriate credit to the original author(s) and the source, provide a link to the Creative Commons licence, and indicate if changes were made. The images or other third party material in this article are included in the article's Creative Commons licence, unless indicated otherwise in a credit line to the material. If material is not included in the article's Creative Commons licence and your intended use is not permitted by statutory regulation or exceeds the permitted use, you will need to obtain permission directly from the copyright holder. To view a copy of this licence, visit http://creativecommons.org/licenses/by/4.0/ The Creative Commons Public Domain Dedication waiver (http://creativecommons.org/publicdomain/zero/1.0/) applies to the data made available in this article, unless otherwise stated in a credit line to the data. 


\section{Introduction}

Over the past decade, there has been an increase in the number of knee arthroplasties performed worldwide. Over a 10-year period the incidence of knee periprosthetic joint infection (PJI) is about $0.75 \%$ at 10 years in primary TKA, accounting for nearly one-fourth in revision cases $[1,2]$. Post-operative complication rate of revision TKA for PJI is high (13.7\%) [3], and 5-year mortality rate is $25.9 \%$ [2].

Patients can be more susceptible to PJI with specific risk factors, such as uncontrolled diabetes [4-6], malnutrition [7], obesity [8], smoking [9], and chronic hepatitis. Chronic hepatitis can induce immune dysfunction and systemic inflammation, causing high incidence of knee PJI. Recent studies have reported high complication rates after hip and knee arthroplasty in patients with chronic hepatitis [10-12].

In early acute PJI, debridement, antibiotic, and implant retention (DAIR) procedure showed satisfying treatment result [13]. Two-stage exchange arthroplasty has been generally used as gold-standard to treat chronic PJI, and the success rate is between 64 and $89.9 \%$ [14-17]. Several risk factors have been reported to be associated with failure of the treatment for knee PJI, including obesity, smoking, heart disease, psychiatric disorders, female gender, and polymicrobial infection [18-20]. In immunocompetent patients whose infecting micro-organism and sensitivity are verified, one-stage exchange arthroplasty can be a valuable choice of treatment [21].

To the best of our knowledge, the efficacy of two-stage exchange arthroplasty in knee PJI patients with chronic hepatitis has not been reported. Chronic viral hepatis has been considered to have poor immune function and a high risk of infection [22]. This study was determined to evaluate the efficacy of two-stage exchange arthroplasty for the treatment of knee PJI. Our hypothesis is that patients with chronic hepatitis will have poorer outcomes after two-stage exchange arthroplasty for knee PJI.

\section{Methods}

\section{Patient enrollment}

We retrospectively reviewed a joint database of arthroplasty to identify patients who were diagnosed with knee PJI and were treated with two-stage exchange arthroplasty at our institution between June, 2010 and December, 2016. Patients who previously received revision surgery in other institutions were excluded.

PJI was defined by fulfilling one of the following three criteria: (1) a sinus tract communicating with the prosthesis; (2) isolated pathogens from two or more samples obtained from the infected prosthetic joint; (3) presence of purulence in the affected joint with elevated synovial white blood cell count and synovial neutrophil percentage (PMN\%) combined with serum erythrocyte sedimentation rate and serum C-reactive protein concentration elevation [23].

Eight surgeons were involved in these operations, all following the same protocol. Pre-operative joint aspiration for microbiology culture was performed in all the enrolled patients. After diagnosis of knee PJI, they were treated with protocol of two-stage exchange arthroplasty. In brief, medial para-patella approach, resection arthroplasty for PJI included radical debridement, removal of prosthesis, antibiotic-loaded bone cement implantation, and administration of systemic antimicrobial agents for controlling joint infection. Vancomycin and Ceftazidime were loaded in Simplex P, Stryker, providing broadspectrum anti-bacterial capacity [24]. All patients were under general anesthesia and torniquet was used in the whole course of operation. Intraoperative samples were sent for microbiology culture. Most of the wound can be closed without difficulty. In some case with potential soft tissue problem, negative pressure tissue therapy system was applied. Delayed re-implantation of the prosthesis after successful antimicrobial therapy was defined as no signs of infection and erythrocyte sedimentation rate and normal levels of serum C-reactive protein [25]. The choice of implant, whether primary or revision system, was based on patients' bone loss and ligament condition.

Two to 4 weeks of antibiotics were used after the implant removal (first stage). Partial weightbearing was recommended in this interim period. One to 3 days of antibiotics were used after re-implantation of prosthesis (second stage). Walking with full weightbearing was allowed immediately after the re-implantation of prosthesis. The choice of regiment was depended on the microbiology culture. The outcome was assessed according to the 2013 Delphi-based International Consensus definition (1) infection eradication, characterized by a healed wound without fistula, drainage, or pain, and no infection recurrence caused by the same organism strain; (2) no subsequent surgical intervention for infection after reimplantation surgery; and (3) no PJI-related mortality caused by sepsis or necrotizing fasciitis.

We also identified patients who were diagnosed with chronic viral hepatitis, including hepatitis B virus (HBV) and hepatitis $\mathrm{C}$ virus (HCV). Patients were further divided into the hepatitis group and the non-hepatitis group (control group). Patients with liver cirrhosis were further identified within these cases, and liver cirrhosis was mainly diagnosed by histological findings. For those who had not undergone liver biopsy, the diagnosis of liver cirrhosis was made by at least two of the followings: (1) abnormal liver functional test (serum albumin $\leq 3.4 \mathrm{~g} /$ $\mathrm{dl}$, international normalized ration $[\mathrm{INR}] \leq 1.3$, or serum bilirubin $\leq 2 \mathrm{mg} / \mathrm{dl}$ ); (2) esophageal varices (EVs) on endoscope, and (3) portal hypertension suggested on 
imaging studies (ultrasonography or computed tomography) [26]. Hepatic function reservation was evaluated by the Child-Turcotte-Pugh (CTP) scoring system [27].

We reviewed patient characteristics (age, sex, BMI), comorbidities, results of microbiologic studies, and final outcomes in all knee PJI patients with or without chronic hepatitis. Approval for this study was obtained from the Institutional Review Board.

\section{Statistical analysis}

The survival analysis was evaluated using Kaplan-Meier survival curve with 95\% confidence interval (CI). The Chi-square test or the Fisher's exact test was used where appropriate to analyze categorical data. Independent ttest or nonparametric Mann-Whitney U-test was applied for between-group comparisons in numerical data. Kaplan-Meier and Cox regression were applied for survival analysis. Statistical significance was defined as $p<$ 0.05 . Due to the small sample size in this study, univariate and two-sided analysis were performed in this study. Statistical analysis was carried out by SPSS 24.0 program for Windows (IBM SPSS Statistics for Windows, Version 24.0; IBM Corp, Armonk, NY, USA).

\section{Results}

Between June, 2010 and December, 2016, 172 knee PJI patients (81 male and 91 female) with an average age of 68 years old (range, 25-87 years) were treated with twostage exchange arthroplasty protocol at our institute. The mean duration of follow-up was 35 months (range, 12-85 months). Twenty-five patients were diagnosed with chronic viral hepatitis (16 HBV and $9 \mathrm{HCV})$, and
147 patients were hepatitis-free. The patients in both groups were homogeneous.

The infection recurrence rate in the hepatitis group (28\%, 7 in 25) was significantly higher than that in the control group (9.5\%, 14 in 147), $p=0.017$. Kaplan-Meier and Cox regression survival analysis showed a significantly higher treatment failure rate in the hepatitis group than in the non-hepatitis group, $p=0.01$ (Fig. 1). There was no significant difference between HBV (24\%, 4 in 16) and HCV groups (33.3\%, 3 in 9). According to the Delphi-based consensus definition, the average infection recurrence time was 7 months (range, 2-14 months) after two-stage exchange arthroplasty. The Charlson Comorbidity Index (CCI) score was significantly higher in the hepatitis group than in the non-hepatitis group (5 vs. $4, p=0.011)$. Details of the patient characteristics are summarized in Table 1.

Regarding the 21 patients with infection recurrence, 4 patients (all in the non-hepatitis group) with infection signs/symptoms less than 3 weeks were treated with the DAIR procedure. One of them experienced treatment failure and took a second two stage exchange arthroplasty. The overall success rate of the first time DAIR in the non-hepatitis group was $75 \%$. The other 17 patients (10 in the non-hepatitis group and 7 in the hepatitis group) with infection relapse sign/symptoms more than 3 weeks received repeated two-stage exchange arthroplasty, with $100 \%$ success rate.

Regarding the microorganisms in the knee PJI, Staphylococcus aureus was the most common pathogen (49 cases, 28.5\%), followed by coagulase negative Staphylococcus (32 cases, 18.6\%), Enterococcus faecalis

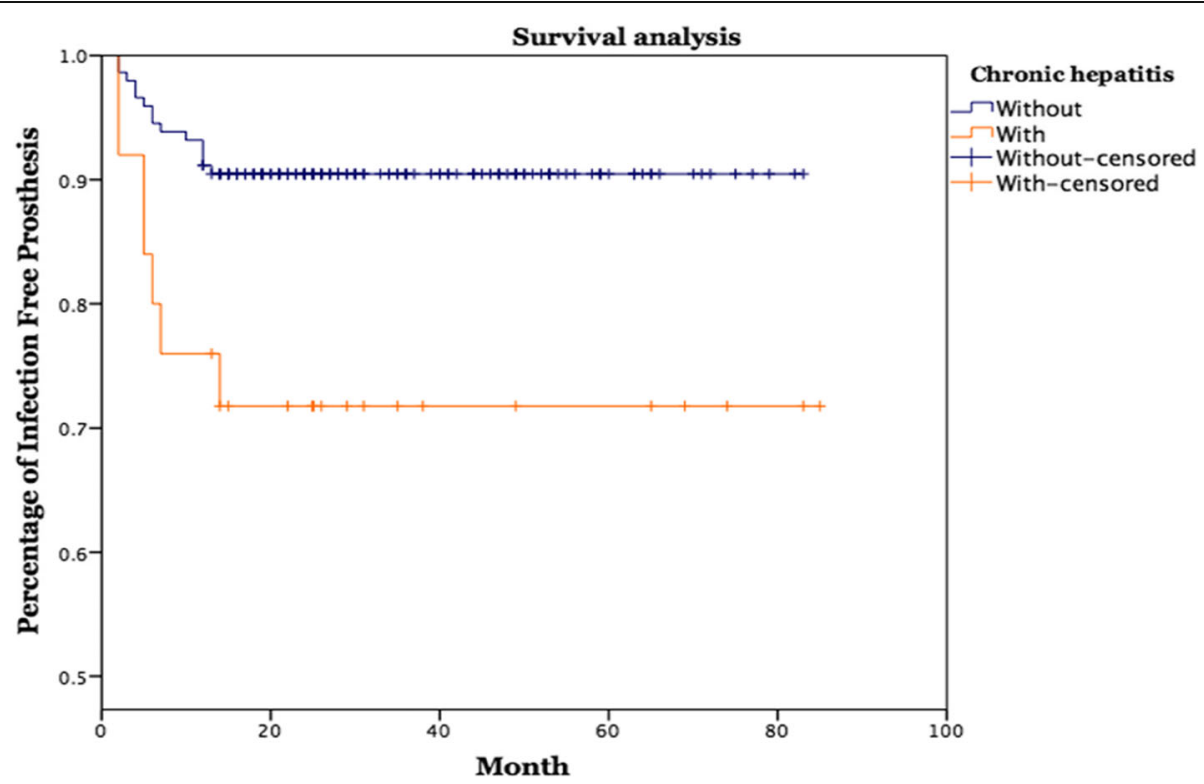

Fig. 1 Kaplan-Meier Survival analysis of knee periprosthetic joint infection treated with two-stage exchange arthroplasty in patient with or without chronic viral hepatitis 
Table 1 Demographics and characteristics of patients with or without chronic hepatitis

\begin{tabular}{llll}
\hline Number & Non-hepatitis & Hepatitis & $\mathbf{P}$ \\
& $\mathbf{1 4 7}$ & $\mathbf{2 5}$ & \\
\hline Age & $68(25-87)$ & $63(30-83)$ & 0.075 \\
Sex & & & 0.922 \\
$\quad$ Male & $69(46.9 \%)$ & $12(48 \%)$ & \\
$\quad$ Female & $78(53.1 \%)$ & $13(52 \%)$ & \\
Follow up months & $34(12-83)$ & $39(13-85)$ & 0.286 \\
Infection relapse PJI & $14(9.5 \%)$ & $7(28 \%)$ & $\mathbf{0 . 0 1 7 * *}$ \\
Charlson comorbidity index & $4(0-11)$ & $5(1-7)$ & $\mathbf{0 . 0 1 1}$ \\
Treatment after failure & & & \\
$\quad$ Second revision & 10 & 7 & \\
DAIR, success & 3 & 0 & \\
DAIR, fail, 2nd revision & 1 & 0 & \\
\hline ** P<0.05 & & &
\end{tabular}

(6 cases, 3.4\%), and Pseudomonas aeruginosa (4 cases, 2.3\%). In sum, 93 cases (54.1\%) were caused by Gram positive bacteria, $12(7.0 \%)$ were Gram negative bacteria, 2 (1.7\%) were Mycobacteria, and 6 (3.5\%) were yeast infection. Fifty-nine cases (34.3\%) were culture-negative. The result is listed in Table 2. There was no significant difference between the two groups.

\section{Discussion}

With the two-stage exchange arthroplasty treatment protocol, a significantly higher incidence of infection recurrence was noted in the hepatitis group compared to

Table 2 Culture result of patients with or without chronic hepatitis

\begin{tabular}{lll}
\hline & Non-hepatitis & Hepatitis \\
\hline Staphylococcus aureus & $39(26.5 \%)$ & $5(20 \%)$ \\
OSSA & $5(3.4 \%)$ & 0 \\
ORSA & $27(18.4 \%)$ & $5(20 \%)$ \\
Coagulase negative Staph. & $3(2.0 \%)$ & 0 \\
Group B Streptococcus & $5(3.4 \%)$ & $1(4 \%)$ \\
Enterococcus faecalis & $2(1.4 \%)$ & 0 \\
Escherichia coli & $4(2.7 \%)$ & 0 \\
Pseudomonas aeruginosa & 0 & $1(4 \%)$ \\
Morganella morganii & 0 & $1(4 \%)$ \\
Parvimonas micra & $2(1.4 \%)$ & $1(4 \%)$ \\
Serratia marcescens & $1(0.7 \%)$ & 0 \\
Pseudomonas stutzeri & $2(1.4 \%)$ & 0 \\
Mycobacterium spp. & $4(2.7 \%)$ & $2(8 \%)$ \\
Yeast spp. & $53(36.1 \%)$ & $9(36 \%)$ \\
Culture negative & &
\end{tabular}

the non-hepatitis group ( $28 \%$ vs. $9.5 \%)$ in this study. For the hepatitis group, whether the pathogen is HBV or HCV does not affect the outcome.

It has been well known that chronic liver disease is associated with higher surgical mortality and morbidity rates. HBV can suppress the production of primary cytokines involved in the innate immune response, disturbance in proliferation processes, and cytokine production [22]. Chronic infection with HCV often develops into liver cirrhosis [28, 29]. Therefore, numerous studies have revealed that chronic liver disease is associated with higher surgical mortality and morbidity rates. In nonorthopedic operation, studies have reported a perioperative mortality rate up to $25 \%$ [30-32]. Furthermore, complications such as bleeding, infection, and multisystem failure have also increased in patients with chronic liver disease [33].

In this study, all seven patients with chronic hepatitis who failed two-stage exchange arthroplasty underwent prosthesis removal and a second two-stage exchange arthroplasty. The patients were followed for at least 21 months in the outpatient department (mean, 37 months; range 21-68 months), and no sign of recurrent PJI was noticed.

Liver cirrhosis has been recognized as a risk factor for hip PJI treatment failure with two-stage exchange arthroplasty [34, 35]. In this study, we further divided knee PJI patients with chronic hepatitis into with or without liver cirrhosis. Demographics of patients are listed in Table 3. Although not significant, the infection recurrence rate was higher in the cirrhosis group than the non-cirrhosis group (100\% vs. $21.7 \%)$. Further investigations may be required to determine whether knee PJI

Table 3 Demographics and characteristics of the hepatitis patients with or without liver cirrhosis

\begin{tabular}{llll}
\hline & Non-cirrhosis & Cirrhosis & $P$ \\
\hline Number & 23 & 2 & \\
Age & $63(30-83)$ & $72(68-76)$ & 0.280 \\
Sex & & & 0.480 \\
$\quad$ Male & $12(52.2 \%)$ & 0 & \\
$\quad$ Female & $11(47.8 \%)$ & $2(100 \%)$ & \\
F/U months & $39(13-85)$ & $36(28-43)$ & 0.837 \\
Infection relapse PJI & $5 / 23(21.7 \%)$ & $2 / 2(100 \%)$ & $0.070^{* *}$ \\
Charlson comorbidity index & $5(1-7)$ & $6(6-6)$ & 0.353 \\
Treatment after failure & & & \\
$\quad$ Second revision & 5 & 2 & \\
DAIR & 0 & 0 & \\
DAIR, failure, 2nd revision & 0 & 0 & \\
Debridement & 0 & 0 & \\
\hline
\end{tabular}


patients with liver cirrhosis should consider other treatment protocols such as fusion or amputation.

According to the Delphi-based International Consensus of PJI 2013, DAIR can be performed on PJI patients who had late hematogenous infection within 3 weeks of an inciting event or symptoms no longer than 3 weeks [36]. In the non-hepatitis group, 4 patients were treated with DAIR, with a success rate of $75 \%$. Several risk factors have been identified as early predictors of treatment failure in the DAIR procedure. Tornero et al. established the Kidney, Liver, Index surgery, Cemented prosthesis and C-reactive protein value (KLIC) score in a retrospective study of 222 procedures [37]. They found 5 independent pre-operative predictors of failure, including chronic kidney disease, liver cirrhosis, infection of a revision arthroplasty or arthroplasty for femoral neck fracture, cemented prosthesis, and presenting C-reactive protein $>11.5 \mathrm{mg} / \mathrm{dL}$. If the KLIC score is greater than 6, DAIR is more likely to fail. Whether DAIR is suitable for patients with chronic viral hepatitis needs more larger-scale and prospective studies in the future.

There are several limitations in this study, including minimum length of one-year follow-up, small sample size, and retrospective study design. Larger prospective randomized controlled trials are needed to confirm whether the selection criteria for two-stage exchange arthroplasty after the first episode of PJI can improve prognosis and quality of life in patients with chronic hepatitis. This study suggests that surgeons can consider two-stage exchange arthroplasty when counseling knee PJI patients with chronic hepatitis, and provides a basis for future studies.

\section{Conclusion}

Knee PJI patients with chronic hepatitis displayed a higher rate of treatment failure (28\%) after two-stage exchange arthroplasty and needed further surgery for infection control.

\section{Acknowledgements}

The authors would like to thank Chang Gung Memorial Hospital Grant (CORPG3H0691, CORPG3J0561, CORPG3J0541) for supporting this research. The staff of the Research Services Center For Health Information, Chang Gung University, Taoyuan, Taiwan, are appreciated for their technical assistance for statistical analysis.

\section{Authors' contributions}

JPC wrote the main manuscript text. YC was the main contributor in updating and revising the original report. $\mathrm{CHC}, \mathrm{YCL}, \mathrm{SHL}$, and HNS took part in reading and approving the final manuscript.

\section{Funding}

We declare that we don't use any external funding.

\section{Availability of data and materials}

The datasets used and analyzed during the current study are available from the corresponding author on reasonable request.

\section{Declarations}

Ethics approval and consent to participate

Informed consent was obtained from all subjects and approval from the Chang Gung medical foundation institutional review board (201902172B0) was acquired. All methods were performed in accordance with Declaration of Helsinki.

Consent for publication

Not applicable.

\section{Competing interests}

The authors declare that they have no competing interests.

\section{Author details}

'Department of Orthopaedic Surgery, Chang Gung Memorial Hospital, Linkou, Taiwan. ${ }^{2}$ College of Medicine, Chang Gung University, Taoyuan, Taiwan. ${ }^{3}$ Bone and Joint Research Center, Chang Gung Memorial Hospital, Linkou, Taiwan. ${ }^{4}$ Department of Orthopaedic Surgery, Chang Gung Memorial Hospital, 5, Fu-Hsin St., Kweishan, Taoyuan, Taiwan.

Received: 16 March 2021 Accepted: 31 May 2021

Published online: 12 June 2021

References

1. Bozic K, Kurtz SM, Lau E, Ong K, Chiu V, Vail TP, et al. The epidemiology of revision total knee arthroplasty in the United States. Clin Orthop Relat Res. 2010;468(1):45-51.

2. Sabah SA, Alvand A, Price AJ. Revision knee replacement for prosthetic joint infection: epidemiology, clinical outcomes and health-economic considerations. Knee. 2021:28:417-21.

3. Boddapati V, Fu MC, Mayman DJ, Su EP, Sculco PK, McLawhorn AS. Revision Total knee Arthroplasty for Periprosthetic joint infection is associated with increased postoperative morbidity and mortality relative to noninfectious revisions. J Arthroplast. 2018:33(2):521-6.

4. Berrou J, Fougeray S, Venot M, Chardiny V, Gautier JF, Dulphy N, et al. Natural killer cell function, an important target for infection and tumor protection, is impaired in type 2 diabetes. PLoS One. 2013;8(4):e62418.

5. Iorio R, Williams KM, Marcantonio AJ, Specht LM, Tilzey JF, Healy WL. Diabetes mellitus, hemoglobin A1C, and the incidence of total joint arthroplasty infection. J Arthroplasty. 2012;27(5):726-729.e721.

6. Tarabichi M, Shohat N, Kheir MM, Adelani M, Brigati D, Kearns SM, et al. Determining the threshold for hba1c as a predictor for adverse outcomes after total joint arthroplasty: a multicenter, retrospective study. J Arthroplasty. 2017;32(9s):S263-S267.e261.

7. Jaberi FM, Parvizi J, Haytmanek CT, Joshi A, Purtill J. Procrastination of wound drainage and malnutrition affect the outcome of joint arthroplasty. Clin Orthop Relat Res. 2008:466(6):1368-71.

8. Parratte S, Pesenti S, Argenson JN. Obesity in orthopedics and trauma surgery. Orthop Traumatol Surg Res. 2014;100(1 Suppl):S91-7.

9. Sorensen LT. Wound healing and infection in surgery: the pathophysiological impact of smoking, smoking cessation, and nicotine replacement therapy: a systematic review. Ann Surg. 2012;255(6):1069-79.

10. Cancienne JM, Kandahari AM, Casp A, Novicoff W, Browne JA, Cui Q, et al. Complication rates after Total hip and knee Arthroplasty in patients with hepatitis C compared with matched control patients. J Am Acad Orthop Surg. 2017:25(12):e275-81.

11. Issa K, Pierce TP, Harwin SF, Scillia AJ, Mclnerney VK, Mont MA. Does hepatitis $C$ affect the clinical and patient-reported outcomes of primary Total hip Arthroplasty at midterm follow-up? J Arthroplast. 2017;32(9): 2779-82.

12. Kildow BJ, Politzer CS, DiLallo M, Bolognesi MP, Seyler TM. Short and longterm postoperative complications following total joint arthroplasty in patients with human immunodeficiency Virus, Hepatitis B, or Hepatitis C. J Arthroplasty. 2017;33(7): S86-S92.

13. Rudelli BA, Giglio PN, de Carvalho VC, Pécora JR, Gurgel HMC, Gobbi RG, et al. Bacteria drug resistance profile affects knee and hip periprosthetic joint infection outcome with debridement, antibiotics and implant retention. BMC Musculoskelet Disord. 2020;21(1):574. 
14. Cochran AR, Ong KL, Lau E, Mont MA, Malkani AL. Risk of reinfection after treatment of infected Total knee Arthroplasty. J Arthroplast. 2016;31(9 Suppl):156-61.

15. Claassen L, Plaass C, Daniilidis K, Calliess T, von Lewinski G. Two-stage revision total knee arthroplasty in cases of periprosthetic joint infection: an analysis of 50 cases. Open Orthop J. 2015:9:49-56.

16. Stammers J, Kahane S, Ranawat V, Miles J, Pollock R, Carrington RW, et al. Outcomes of infected revision knee arthroplasty managed by two-stage revision in a tertiary referral Centre. Knee. 2015;22(1):56-62.

17. Di Benedetto P, Di Benedetto ED, Buttironi MM, De Franceschi D, Beltrame A, Gissoni R, et al. Two-stage revision after total knee arthroplasty. Acta Bio Medica. 2017:88(2 -s):92-7.

18. Bozhkova S, Tikhilov R, Labutin D, Denisov A, Shubnyakov I, Razorenov V et al. Failure of the first step of two-stage revision due to polymicrobial prosthetic joint infection of the hip. J Orthop Traumatol. 2016;17(4):369-76.

19. Hoell S, Sieweke A, Gosheger G, Hardes J, Dieckmann R, Ahrens H, et al. Eradication rates, risk factors, and implant selection in two-stage revision knee arthroplasty: a mid-term follow-up study. J Orthop Surg Res. 2016; 11(1):93.

20. Triantafyllopoulos GK, Memtsoudis SG, Zhang W, Ma Y, Sculco TP, Poultsides LA. Periprosthetic infection recurrence after 2-stage exchange Arthroplasty: failure or fate? The Journal of arthroplasty; 2016.

21. Pellegrini $A$, Meani $E$, Macchi $V$, Legnani $C$. One-stage revision surgery provides infection eradication and satisfying outcomes for infected knee arthroplasty in selected patients. Expert Rev Anti-Infect Ther. 2020;18:1-4

22. Balmasova IP, Yushchuk ND, Mynbaev OA, Alla NR, Malova ES, Shi Z, et al. Immunopathogenesis of chronic hepatitis B. World J Gastroenterol. 2014; 20(39):14156-71.

23. Parvizi J. New definition for periprosthetic joint infection. Am J Orthop. 2011:40(12):614-5.

24. Hsu YH, Hu CC, Hsieh PH, Shih HN, Ueng SW, Chang Y. Vancomycin and Ceftazidime in bone cement as a potentially effective treatment for knee Periprosthetic joint infection. J Bone Joint Surg Am. 2017;99(3):223-31.

25. Wheat J, Sarosi G, McKinsey D, Hamill R, Bradsher R, Johnson P, et al. Practice guidelines for the management of patients with histoplasmosis. Infectious Diseases Society of America. Clin Infect Dis. 2000;30(4):688-95.

26. Teh SH, Nagorney DM, Stevens SR, Offord KP, Therneau TM, Plevak DJ, et al. Risk factors for mortality after surgery in patients with cirrhosis. Gastroenterology. 2007;132(4):1261-9.

27. Pugh RN, Murray-Lyon IM, Dawson JL, Pietroni MC, Williams R. Transection of the oesophagus for bleeding oesophageal varices. Br J Surg. 1973;60(8): 646-9.

28. Seeff LB, Buskell-Bales Z, Wright EC, Durako SJ, Alter HJ, Iber FL, et al. Longterm mortality after transfusion-associated non-a, non-B hepatitis. The National Heart, Lung, and Blood Institute study group. N Engl J Med. 1992; 327(27):1906-11.

29. Kanwal F, Hoang T, Kramer JR, Asch SM, Goetz MB, Zeringue A, et al. Increasing prevalence of HCC and cirrhosis in patients with chronic hepatitis C virus infection. Gastroenterology. 2011;140(4):1182-1188.e1181.

30. Rice HE, O'Keefe GE, Helton WS, Johansen K. Morbid prognostic features in patients with chronic liver failure undergoing nonhepatic surgery. Arch Surgery. 1997;132(8):880-4 discussion 884-885.

31. Friedman LS. The risk of surgery in patients with liver disease. Hepatology. 1999;29(6):1617-23.

32. Neves J, de Araujo NM, Oliveira P. Martins dos Santos J, Malo P: risk factors for implant failure and Peri-implant pathology in systemic compromised patients. J Prosthodont. 2016;27(5):409-15.

33. Ziser A, Plevak DJ, Wiesner RH, Rakela J, Offord KP, Brown DL. Morbidity and mortality in cirrhotic patients undergoing anesthesia and surgery. Anesthesiology. 1999;90(1):42-53.

34. Jhan SW, Lu YD, Lee MS, Lee CH, Wang JW, Kuo FC. The risk factors of failed reimplantation arthroplasty for periprosthetic hip infection. BMC Musculoskelet Disord. 2017;18(1):255.

35. Chen SY, Hu CC, Chen CC, Chang YH, Hsieh PH. Two-stage revision Arthroplasty for Periprosthetic hip infection: mean follow-up of ten years. Biomed Res Int. 2015;2015:345475.

36. Haasper C, Buttaro M, Hozack W, Aboltins CA, Borens O, Callaghan JJ, et al. Irrigation and debridement. J Arthroplast. 2014;29(2 Suppl):100-3.

37. Tornero E, Morata L, Martinez-Pastor JC, Bori G, Climent C, Garcia-Velez DM, et al. KLIC-score for predicting early failure in prosthetic joint infections treated with debridement, implant retention and antibiotics. Clin Microbiol Infect. 2015;21(8):786.e789-17.

\section{Publisher's Note}

Springer Nature remains neutral with regard to jurisdictional claims in published maps and institutional affiliations.
Ready to submit your research? Choose BMC and benefit from:

- fast, convenient online submission

- thorough peer review by experienced researchers in your field

- rapid publication on acceptance

- support for research data, including large and complex data types

- gold Open Access which fosters wider collaboration and increased citations

- maximum visibility for your research: over $100 \mathrm{M}$ website views per year

At BMC, research is always in progress.

Learn more biomedcentral.com/submissions 